\title{
Citotoxicidade de uma formulação em orabase de Libidibia Ferrea
}

\author{
Cytotoxicity of an orabase from Libidibia Ferrea \\ Citotoxicidad de una orabasa de Libidibia Ferrea
}

Recebido: 25/07/2021 | Revisado: 30/07/2021 | Aceito: 01/08/2021 | Publicado: 07/08/2021

\author{
Glauber Palma de Oliveira \\ ORCID: https://orcid.org/0000-0002-4242-9820 \\ Universidade Federal do Amazonas, Brasil \\ E-mail: glauberpoliveira@hotmail.com \\ Letícia da Silva Soares Gomes \\ ORCID: https://orcid.org/0000-0002-8040-1255 \\ Universidade Federal do Amazonas, Brasil \\ E-mail: leticiasoaressz@gmail.com \\ Gisely Naura Venâncio \\ ORCID: https://orcid.org/0000-0001-9756-140X \\ Secretaria Municipal de Saúde, Brasil \\ E-mail: leticiasoaressz@gmail.com \\ Emerson Silva Lima \\ ORCID: https://orcid.org/0000-0002-9367-2812 \\ Universidade Federal do Amazonas, Brasil \\ E-mail: eslima@ufam.edu.br \\ Tatiane Pereira de Souza \\ ORCID: https://orcid.org/0000-0003-2821-5241 \\ Universidade Federal do Amazonas, Brasil \\ E-mail: tpsouza@ufam.edu.br \\ Maria Fulgência Costa Lima Bandeira \\ ORCID: https://orcid.org/0000-0002-9847-5578 \\ Universidade Federal do Amazonas, Brasil \\ E-mail: fulgencia@ufam.edu.br \\ Carina Toda \\ ORCID: https://orcid.org/0000-0003-1709-0877 \\ Universidade Federal do Amazonas, Brasil \\ E-mail: carinatoda@yahoo.com.br \\ Nikeila Chacon de Oliveira Conde \\ ORCID: https://orcid.org/0000-0003-3756-2085 \\ Universidade Federal do Amazonas, Brasil \\ E-mail: nikeilaconde @gmail.com
}

\section{Introdução}

A Libidibia Ferrea é uma planta que possui inúmeras propriedades terapêuticas comprovadas para prevenção e tratamento de afecções bucais. Objetivo: Avaliar uma formulação em orabase de Libidibia ferrea quanto a citotoxicidade. Metodologia: O teste de hemólise foi realizado através do método de avaliação qualitativa de hemoglobina livre e o teste de cultura de células de fibroblastos através do método de Alamar Blue. Foram testados o extrato da casca do caule, veículo da formulação, seus adjuvantes e a formulação orabase. Resultados: No teste de hemólise tanto o extrato da casca do caule quanto a formulação e seus componentes não apresentaram hemólise ao avaliar visualmente o sobrenadante de cada poço. No teste de Alamar Blue não apresentou toxicidade em nenhuma das soluções testadas. Conclusão: Baseado nos resultados, o extrato da casca do caule e a formulação em orabase de Libidibia ferrea $L$. não foram tóxicos quando testados em hemácias e cultura de células de fibroblastos.

Palavras-chave: Fitoterapia; Citotoxicidade; Jucá.

\begin{abstract}
Introduction: Libidibia Ferrea is a plant with proven therapeutic properties for the prevention and treatment of oral diseases. Objective: To evaluate an orabase source of Libidibia ferrea for cytotoxicity. Methodologys: The hemolysis test was performed using the qualitative assessment method of free hemoglobin and the fibroblast cell culture test using the Alamar Blue method. The stem bark extract, base vehicle, its adjuvants and orabase base were tested. Results: No hemolysis test either the stem bark extract or the above and its components did not dissipate hemolysis when visually evaluating the supernatant from each well. In the Alamar Blue test, it did not show toxicity in any of the tested solutions. Conclusion: Based on the results, the stem bark extract and the orabase base of Libidibia ferrea L. were not toxic when tested in red blood cells and fibroblast cell cultures.
\end{abstract}

Keywords: Phytotherapy; Cytotoxicity; Jucá. 


\begin{abstract}
Resumen
Introducción: Libidibia Ferrea es una planta con probadas propiedades terapéuticas para la prevención y el tratamiento de enfermedades bucodentales. Objetivo: evaluar una fuente de orabasa de Libidibia ferrea para la citotoxicidad. Metodología: La prueba de hemólisis se realizó mediante el método de evaluación cualitativa de hemoglobina libre y la prueba de cultivo celular de fibroblastos mediante el método Alamar Blue. Se ensayaron el extracto de corteza del tallo, el vehículo base, sus adyuvantes y la base de orabasa. Resultados: No se realizó prueba de hemólisis ni el extracto de corteza del tallo ni lo anterior y sus componentes no disiparon la hemólisis al evaluar visualmente el sobrenadante de cada pocillo. En la prueba de Alamar Blue, no mostró toxicidad en ninguna de las soluciones probadas. Conclusión: Según los resultados, el extracto de corteza de tallo y la base de orabasa de Libidibia ferrea L. no fueron tóxicos cuando se probaron en cultivos de glóbulos rojos y fibroblastos.
\end{abstract}

Palabras clave: Fitoterapia, Citotoxicidad, Jucá.

\title{
1. Introdução
}

As úlceras ou aftas traumáticas são geralmente as lesões mais comuns dos tecidos moles da boca, causadas pelo trauma mecânico, onde se observa a relação direta entre a causa e efeito. Situam-se com maior frequência no lábio inferior, mucosa jugal e língua. No tratamento dessas lesões da mucosa oral, principalmente naquelas onde existe o envolvimento imunológico, tem ocorrido uma predileção de tratamento pelo uso de pomadas a base de corticosteroides sintéticos (Acetonido de Triancinolona a 1\%), geralmente em orabase (Tommasi, 1982; Regezi et al., 2003)

A fitoterapia através dos estudos com extratos de plantas medicinais tem avançado na Odontologia, pelas diversas aplicabilidades e ações terapêuticas, possibilidade de uso para o controle dos microrganismos do biofilme dental, e a busca de prevenção e tratamento para diversas afecções bucais. Na região Amazônica, existe uma grande biodiversidade de plantas medicinais utilizadas de maneira empírica, porém com indicações consolidadas por séculos de interação cultural. Dentre muitas plantas medicinais se destacam aquelas utilizadas como anti-inflamatório e antimicrobiano (Oliveira et al., 2013; Carvalho et al., 2018; Borrás, 2003)

A espécie Libidibia ferrea L., comum na Amazônica conhecida popularmente como jucá ou pau-ferro vem sendo muito usada na medicina popular. A partir de porções da planta como a casca do caule e vagem, são realizadas preparações que possuem ação cicatrizante e propriedades anti-inflamatórias, analgésicas, antimicrobiana e cicatrizante já comprovadas por diversos estudos (Sampaio et al., 2009; De Araújo et al., 2014). Além disso, a análise do perfil fitoquímico do extrato hidroalcóolico de Libidibia ferrea L. em estudos de identificação por cromatografia, demonstrou a presença de componentes isolados pertencentes ao grupo dos esteroides, flavonoides, saponinas, cumarinas e taninos, sendo os principais componentes químicos relacionados as propriedades terapêuticas do Jucá, os taninos (Falcão et al., 2019; Conde et al., 2015; Pereira et al., 2012; Pedrosa et al., 2016)

No processo de validação e avaliação de um produto é necessário comprovar sua efetividade, os benefícios de seu uso e possíveis riscos à saúde humana, de animais e ao ambiente. Dessa forma, os ensaios toxicológicos visam avaliar a segurança e o risco/benefício do uso terapêutico de formulações (Evans, 2009; Nóbrega et al., 2008). Torna-se crescente o interesse por testes in vitro, os quais antecedem teste in vivo e que não utilizem animais de laboratório (ISO, 2003)

Sendo assim, novas formulações tem sido avaliadas para melhoria no tratamento de lesões bucais traumáticas, objetivando uma modulação do processo inflamatório concomitante a otimização do processo cicatricial. Este estudo justificase como avaliação preliminar em relação ao potencial citotóxico de uma formulação de pomada orabase de Libidibia ferrea a ser utilizada para fins terapêuticos sobre úlceras traumáticas. 


\section{Metodologia}

O estudo trata-se de uma pesquisa de natureza experimental, in vitro e quantitativa. Pereira et al. (2018) denotam que a pesquisa de natureza quantitativa é aquela que utiliza os dados coletados por meio do uso de medições de grandezas que são obtidas por meio da metrologia (números e suas respectivas unidades). Portanto, fez-se necessário a aplicação dos respectivos métodos para teste e análise dos resultados obtidos a partir dos objetivos propostos.

Os materiais vegetais casca do caule e a vagem da espécie vegetal Libidibia ferrea $L$. foram coletadas na cidade de Manaus em locais como o Instituto Nacional de Pesquisas da Amazônia (INPA), estrada BR-174, KM 42 e estrada BR AM 104. O INPA realizou a identificação botânica recebendo o código de registro de número 228.022. Posteriormente, as matériasprimas foram processadas na Faculdade de Ciências Farmacêuticas (FCF/UFAM) conforme a metodologia descrita por Melo (2010).

\section{Formulação da pomada orabase}

A nova formulação foi proposta a partir da concentração inibitória mínima determinada na fase inicial da pesquisa do extrato da casca do caule de Jucá, o qual apresentou melhores resultados frente aos microrganismos testados (Oliveira, 2013). A composição da formulação obedeceu aos mesmos padrões das pomadas orabases atualmente utilizadas no mercado, porém com a inclusão do extrato seco da Libidibia ferrea como componente bioativo.

A formulação proposta apresenta duas fases na sua composição, a oleosa e a aquosa. O componente da fase oleosa, representada pelo gel de petrolato/polietileno associado ao óleo mineral, correspondendo a $40 \%$ da composição. Enquanto que a fase aquosa, representando $60 \%$ do total é composta por CarboxiMetilCelulose (0,5\%); Metilparabeno (0,15\%); Água destilada qsp. A apresentação da pomada foi em potes contendo $10 \mathrm{~g}$, contendo como componente bioativo o extrato seco de Libidibia ferrea a $10 \%$.

\section{Teste de Hemólise}

A atividade hemolítica do extrato da casca do caule e da formulação orabase do jucá, bem como de todos os constituintes adjuvantes de tal formulação, foi avaliada de acordo com a metodologia descrita por Fischer (2003) modificado.

Foi coletado $1 \mathrm{~mL}$ de sangue em tubos heparinizados de ratos Wistar e diluído em $10 \mathrm{~mL}$ de solução salina (cloreto de cálcio e de sódio). Em seguida, centrifugado a 1.126 g (1500 rpm) por 5 min (Centrifuge 5804R - Eppendorf), após a remoção do sobrenadante o sangue foi ressuspendido em $10 \mathrm{~mL}$ de solução salina e centrifugado novamente. Após o terceiro ciclo de centrifugação a lavagem de eritrócitos foi concluída. Uma solução eritrocitária a $2 \%$ foi obtida a partir do sedimento de hemácias mantidas no tubo de ensaio. Em $50 \mathrm{~mL}$ de solução salina uma alíquota de $1000 \mu \mathrm{L}$ foi ressuspendida.

A amostra da formulação foi preparada em uma proporção de $200 \mathrm{mg} / \mathrm{mL}$ de DMSO foram utilizados $10 \mu \mathrm{L}$. Nos casos dos componentes adjuvantes da formulação CMC (carboximetilcelulose) e crodabase foram utilizados $400 \mu \mathrm{L}$ e $10 \mu \mathrm{L}$, respectivamente.

As diluições das substâncias testes, DMSO, solução salina e Triton 0,2\% foram adicionados em placa de 96 poços em colunas padronizadas (Figura 1). Foi adicionado um volume final de $100 \mu \mathrm{L}$ de cada substância teste diluída $+100 \mu \mathrm{L}$ de solução eritrocitária a 2\%. Na linha A foi testada a Carboximetilcelulose, na linha B o extrato de jucá, na C o veículo da formulação, na D a formulação propriamente dita. Nas linhas F e G foram testados os controles negativos, os quais serviram de diluentes dos compostos acima, sendo o DMSO e água destilada, respectivamente. Como controle positivo foi testado o Triton na linha $\mathrm{H}$. 
Figura 1. Representação esquemática do preenchimento da placa de 96 poços do teste de hemólise.

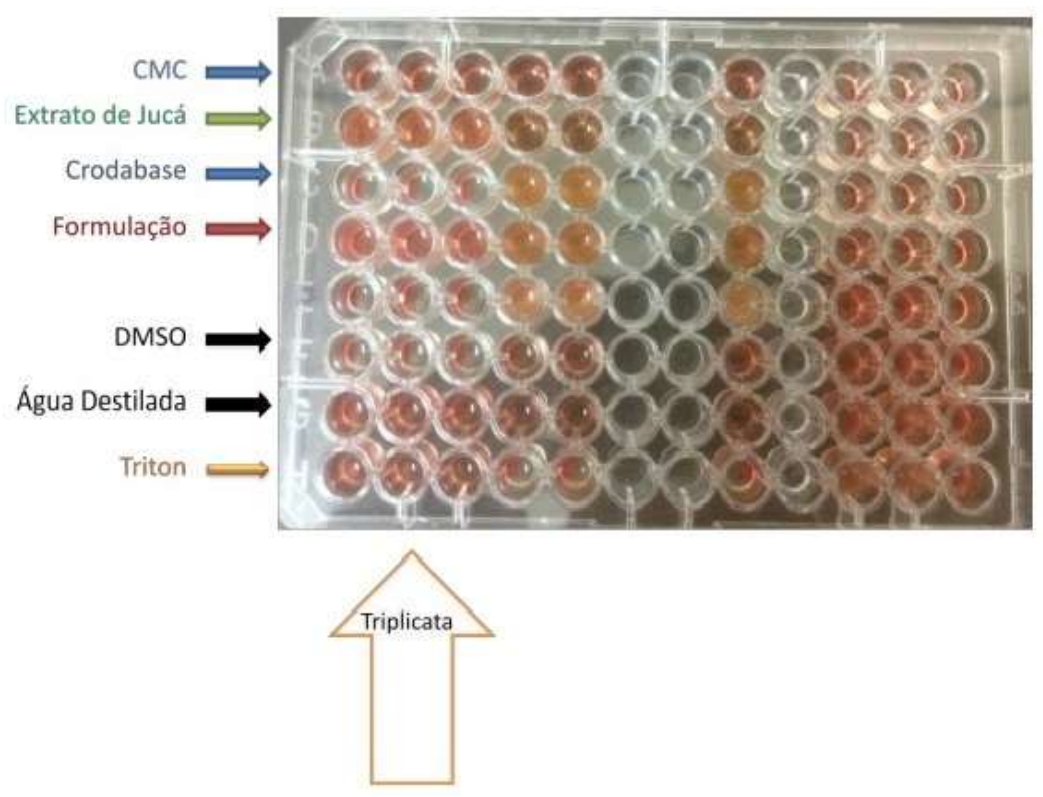

Fonte: Autores.

A placa foi incubada por uma hora sob agitação constante a temperatura ambiente $\left(25^{\circ} \mathrm{C}\right) \mathrm{e}, \mathrm{em}$ seguida, centrifugada a $900 \mathrm{~g}(1500 \mathrm{rpm})$ durante 10 minutos. Então, transferiu-se o sobrenadante para outra placa e realizou-se a leitura em espectrofotômetro a 540nm (Multimode Detector DTX 800 - Beckman Coulter).

\section{Teste de Cultura de Células}

Foram utilizados fibroblastos MRC-5 fornecidos pela Faculdade de Ciências Farmacêuticas da UFAM e o teste foi realizado de acordo com a metodologia descrita por Ahmed (1994) modificado.

Antes da manipulação foi realizada antissepsia com álcool $70 \%$ do fluxo e de todos os materiais nele inseridos. As células foram cultivadas em garrafas e mantidas em estufa com atmosfera úmida com $5 \%$ de $\mathrm{CO}_{2}$ e manipuladas em fluxo laminar. O ensaio de azul de Alamar foi realizada com células da linhagem MRC-5, a partir de fibroblastos de pulmão fetal. Elas foram semeadas em placas de 96 poços $\left(0,5\right.$ x 104 células por poço) e incubadas numa atmosfera de $\mathrm{CO}_{2}$ a $5 \%$ e $37^{\circ} \mathrm{C}$. Após 24 horas, as células foram tratadas com o extrato da casca de jucá, o veículo da orabase, a carboximetilcelulose (CMC), o metilparabeno e a formulação propriamente dita em uma concentração mãe de $50 \mu \mathrm{g} / \mathrm{mL}$ e sete diluições sucessivas e incubouse durante 72 h. Antes do fim da incubação, $10 \mu \mathrm{L}$ de azul de Alamar (0,02\%) foi adicionado a cada poço. O sinal de fluorescência foi monitorada utilizando um leitor multiplacas usando excitação a $530 \mathrm{~nm}$ e emissão a $590 \mathrm{~nm}$ de comprimento de onda. O sinal de fluorescência gerado a partir do ensaio foi proporcional ao número de células vivas na amostra, de acordo com a fabricação. A doxorrubicina foi utilizada como droga padrão CI50 2,23 $\mu \mathrm{M}$. Os valores de IC50 e seus intervalos de confiança de 95\% (IC 95\%) foram obtidos por regressão não-linear.

\section{Análise estatísica dos dados}

Os resultados obtidos nos testes de hemólise foram tabulados e apresentados através da Estatística Descritiva, utilizando médias, desvio-padrão, gráficos e tabelas. Para o teste de cultura de células os resultados foram obtidos por regressão não-linear com valores de IC50 e seus intervalos de confiança de 95\% (IC 95\%). 


\section{Resultados e Discussão}

Os controles empregados aos fitoterápicos são semelhantes àqueles exigidos nos medicamentos convencionais, nos quais as análises são realizadas a fim de obter informações sobre aspectos botânicos, químicos, físico-químicos, biológicos e microbiológicos tanto da matéria-prima vegetal, quanto de seus adjuvantes tecnológicos, materiais de acondicionamento e na forma padronizada, em fase de processamento e em fase final (Gil, 2007). O presente estudo avaliou a atividade de citotoxicidade e da formulação em orabase para avaliação inicial do produto proposto.

Um ensaio de citotoxicidade realizado foi o teste de hemólise visando avaliar o potencial dos produtos testes (o extrato da casca do caule de jucá, veículo da formulação, componente adjuvante e formulação de orabase) em causar lesões na membrana plasmática de hemácias.

Os resultados demonstraram, após análise qualitativa, que ocorreu hemólise completa no controle positivo, enquanto que os controles negativos não apresentaram ruptura de hemácias. Com relação ao extrato, veículo da formulação, CMC, e a formulação de orabase, nenhum apresentou hemólise visualmente em leitura no espectofômetro, ao avaliar o sobrenadante de cada poço. Verificou-se um sobrenadante com ausência de hemoglobina e eritróticos sedimentados (Figura 2). Tais resultados são satisfatórios com relação ao potencial tóxico em células do sangue.

Figura 2. Sobrenadante com ausência de hemoglobina e eritrócitos sedimentados.

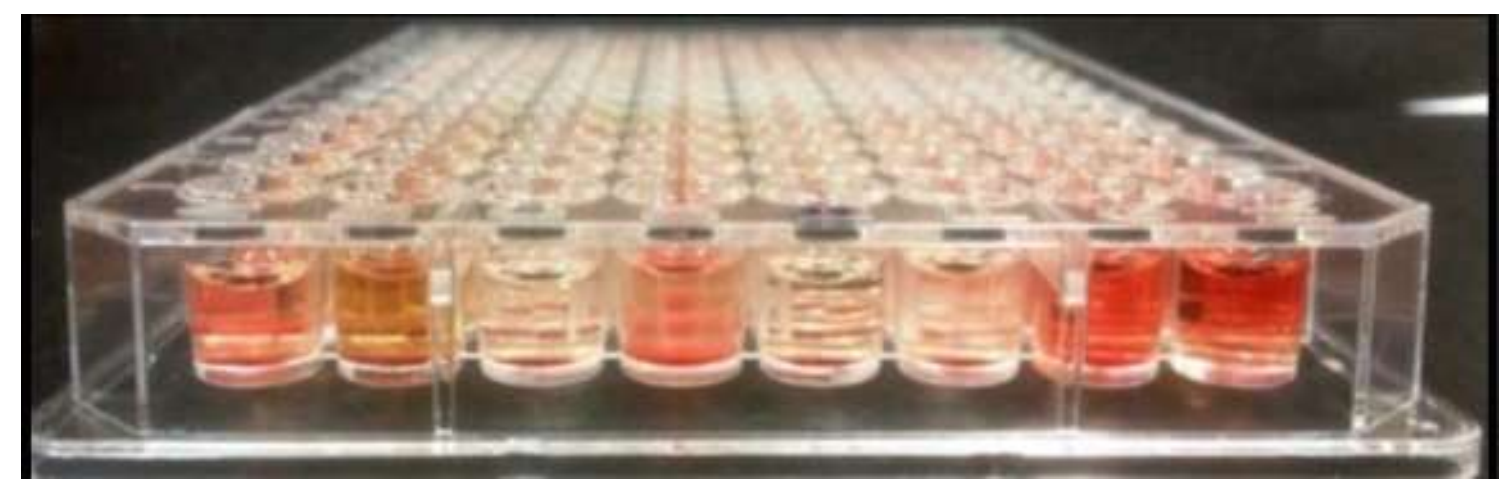

Fonte: Autores.

Os resultados do teste de cultura de células pelo método de Alamar Blue foram avaliadas a viabilidade das células frente ao extrato da casca do caule, veículo da formulação, seus adjuvantes e a formulação orabase de Libidibia ferrea L. O tratamento correspondeu ao período de 72 horas em cultura de fibroblastos (MRC-5) e a doxorrubicina foi utilizada como droga padrão CI50 2,23 $\mu \mathrm{M}$. Após análise dos resultados foi possível verificar (Tabela 1) que nenhuma amostra testada apresentou efeito citotóxico quando em contato com as células, com percentuais de viabilidade celular acima de $81,25 \%$. 
Tabela 1. Percentual de Viabilidade celular da linhagem de fibroblasto humano MRC5.

\begin{tabular}{c|c|c|c|c|c}
\hline & CMC & NIPAGIN & EXTRATO & CRODABASE & FORMULAÇÃO \\
\hline CONTROLE & 100 & 100 & 100 & 100 & 100 \\
\hline 0,78 & 100 & 100 & 100 & 100 & 100 \\
\hline 1,56 & 100 & 100 & 100 & 100 & 100 \\
\hline 3,13 & 100 & 100 & 100 & 94,68 & 100 \\
\hline 6,25 & 100 & 100 & 100 & 93,31 & 100 \\
\hline 12,5 & 100 & 100 & 98,86 & 93,62 & 100 \\
\hline 25 & 94,28 & 100 & 96,08 & 94,41 & 100 \\
\hline 50 & 83,72 & 100 & 81,25 & 90,35 & 100 \\
\hline
\end{tabular}

Fonte: Autores.

Martins et al., (2009) avaliou a citotoxicidade do extrato de arnica brasileira e paulista sobre fibroblastos de mucosa bucal humana (FMM1) cultivados, para a utilização sobre úlceras bucais. Obteve resultados satisfatórios no período de 24 horas de contato das células com as amostras testadas, constatou-se um percentual de lise celular de 16,88\% para arnica brasileira e 43,46\% para a arnica paulista. Então, concluiu que os extratos foram biocompatíveis in vitro sobre fibroblastos da mucosa bucal humana e que devem ser realizados testes in vivo para verificar sua ação anti-inflamatória e reparadora.

Marreiro et al., (2014) obteve resultados utilizando a mesma metodologia de ensaio de citotoxicidade usada neste estudo, avaliando o extrato da vagem, veículo e uma formulação comercial de enxaguatório de jucá. Os testes demostraram que ambas as formulações (enxaguante bucal e veículo de L. ferrea) foram citotóxicas causando a morte dos fibroblastos. O enxaguante bucal apresentou célula de viabilidade de $8 \%$ e o veículo de $7 \%$ quando comparado com o controle positivo. No entanto, quando o estudo foi realizado in vivo, a toxicidade do produto não apresentou alterações inflamatórias. O teste de hemólise também foi realizado por Marreiro onde foram testados o extrato da vagem, veículo e uma formulação comercial de enxaguatório de Jucá. Apesar de uma baixa porcentagem de hemólise para o extrato de jucá, na maior concentração testada $(300 \mu \mathrm{g} / \mathrm{mL})$, a porcentagem de hemólise apresentou uma média de 5,99\% +/- 3,21 e para o veículo $(30 \mu \mathrm{L} / \mathrm{mL})$ e a formulação comercial de enxaguatório de jucá $(10 \mu \mathrm{L} / \mathrm{mL})$ essa média foi de, respectivamente, 5,99\% +/- 3,21 e 14,44\% +/-9,72. As soluções testes apresentaram-se satisfatórias, visto que todas apresentaram porcentagem de hemólise abaixo de 50\%. Tal fato pode ter ocorrido pela concentração de extrato na formulação de orabase (10\%) ser menor quando comparado à concentração da formulação de enxaguatório testada, além de apresentar um maior número de adjuvantes farmacotécnicos.

O estudo de Venâncio et al., (2020) realizou análise da formulação do enxaguante bucal com base no extrato de $L$. ferrea utilizando citotoxicidade. No teste de hemólise foi constatado que o enxaguante bucal de $L$. ferrea não mostrou atividade hemolítica nos tempos estudados. No entanto, o veículo e os enxaguantes bucais de clorexidina de $0,12 \%$ causaram hemólise com EC50 de 75,14 e 300,5 $\mu \mathrm{g} / \mathrm{mL}$, respectivamente. Um resultado considerado satisfatório uma vez que a concentração de veículo na formulação de enxaguante bucal é menor do que o efetivo concentração de hemólise. No estudo também realizou o método Alamar BlueTM para teste de cultura de células, foi constatado que nenhuma amostra testada foi 
capaz de induzir um efeito citotóxico em contato com as células. Os valores de IC50 acima de $50 \mu \mathrm{g} / \mathrm{mL}$ demonstraram ausência de citotoxicidade nas condições testadas.

No estudo de Pereira et al. (2020) que teve por objetivo avaliar a citotoxicidade do extrato metanólico de Psidium guineense por hemólise para avaliar o potencial de toxicidade desta planta, demonstrou-se através dos resultados que o extrato metanólico de $P$. guineense apresentou percentual abaixo de $10 \%$ de hemólise em todas as diferentes concentrações em comparação com o controle positivo, para todos os tipos de eritrócitos testados do sistema $\mathrm{ABO}$ de células sanguíneas humanas, o que sugere baixa toxicidade frente aos eritrócitos humanos testados in vitro, sendo este produto natural considerado uma opção viável para a indústria de medicamentos fitoterápicos.

Na fabricação de uma forma semi-sólida há que se considerar como testes de controle de qualidade: - características organolépticas, envolvendo aspectos visuais como transparência, cor e aspectos sensoriais, comportamento reológico por meio de teste de espalhabilidade, consistência, penetrabilidade, plasticidade e brilho, coalescência, homogeneidade, $\mathrm{pH}$ e doseamento do fármaco (Brasil, 2004). Assim, a partir dos resultados obtidos da formulação proposta em relação a citotoxicidade, os testes de controle de qualidade, assim como teste de biocompatibilidade em modelo animal são as próximas etapas a serem realizadas, para padronização dessa formulação.

\section{Conclusão}

De acordo com os resultados obtidos nos ensaios realizados, foi possível concluir que o extrato do caule do jucá, a formulação em orabase proposta de Libidibia ferrea, assim como o seu veículo e adjuvantes não se apresentaram citotóxicos quando em contato com hemácias e fibroblastos em cultura de células.

Sendo assim, ainda são necessários estudos complementares e auxiliares como teste de toxicidade in vivo para elucidar aspectos de ação dessa formulação em orabase, além de testes em fase de ensaios clínicos que comprovem o real potencial como produto eficaz e aplicável na área odontológica, enriquecendo o patrimônio biológico e natural do Brasil, através da fitoterapia, com a utilização de uma espécie nativa da amazônica com potencial terapêutico na clínica odontológica.

\section{Agradecimentos}

Este trabalho foi financiado por uma bolsa da CAPES (Coordenação de Aperfeiçoamento de Pessoal de Nível Superior), Ministério da Educação do Brasil e Universidade Federal do Amazonas-UFAM (Universidade Federal do Amazonas).

\section{Referências}

Tommasi, F. A. Diagnóstico em Patologia Bucal. Artes Médicas, 1982.

Regezi, J. A. et al. (2003). Oral Pathology: clinical pathologic correlaction. (4a ed.), W. B. Saunders.

Oliveira, G. P. et al. (2008) Antimicrobial activity in vitro of extracts of the stem bark and fruit of Libidibia ferrea L. against microorganisms of the oral cavity. Revista Fitos. 8(2),73-160.

Carvalho, A. C. B., et al. (2018). The Brazilian market of herbal medicinal products and the impacts of the new legislation on traditional medicines. $J$. Ethnopharmacol. (212), 29-35.

Borrás, M. R. L. (2003) Plantas da Amazônia: Medicinais ou mágica? - Plantas comercializadas no mercado Adolpho Lisboa. Valer/Governo do Estado do Amazonas.

Sampaio, F. C., et al. (2009) In vitro antimicrobial activity of Caesalpinia ferrea Martius fruits against oral pathogens. J Ethnopharmacol, $124(2), 28994$.

De Araújo, A. A. et al. Quantification of polyphenols and evaluation of antimicrobial, analgesic and anti-inflammatory activities of aqueous and acetone-water extracts of Libidibia ferrea, Parapiptadenia rigida and Psidium guajava. J Ethnopharmacol, 156, 88-96. 
Research, Society and Development, v. 10, n. 10, e133101018713, 2021

(CC BY 4.0) | ISSN 2525-3409 | DOI: http://dx.doi.org/10.33448/rsd-v10i10.18713

Falcão, T. R., et al. Crude extract from Libidibia ferrea (Mart. ex. Tul.) L.P. Queiroz leaves decreased intra articular inflammation induced by zymosan in rats. BMC Complementary and Alternative Medicine, 19(47), 1-10.

Conde, N. C. O., et al.(2015). In vitro antimicrobial activity of plants of the Amazon on oral biofilm micro-organisms. Rev Odonto Cienc, 30(41),79-183. 2015.

Pereira, L. P., et al. Polysaccharide fractions of Caesalpinia ferrea pods: Potential antiinflammatory usage. J Ethnopharm. 139, 642-48.

Pedrosa, T. B., et al. (2016). Anti-wrinkle and anti- whitening effects of jucá (Libidibia ferrea Mart.) extracts. Archives of Dermatological Research. 308, 643654 .

Evans, G. O. (2009). Animal clinical chemistry: a practical handbook for toxicologists and biomedical researchers. CRC Press.

Nóbrega, AM et al. (2008). Avaliação da irritabilidade ocular induzida por ingredientes de cosméticos através do teste de Draize e dos Métodos HET-CAM e RBC. Universitas: Ciências da Saúde, 6, 103-120.

ISO 10993-1 (2003). Biological evaluation of medical devices. Part 1: Evaluation and testing. International Standard, n. 3.

Pereira, A. S. et al. (2018). Metodologia da pesquisa científica.e-book]. Santa Maria. Ed.UAB/NTE/UFSM. Disponível em: https://repositorio.ufsm.br/bitstream/handle/1/15824/Lic_Computacao_Metodologia-Pesquisa- Cientifica.pdf?sequence=1. Acesso em: 01 de Agosto de 2021.

Melo, Y., et al. (2010). Morfologia de nectários em Leguminosae senso lato em áreas de caatinga no Brasil. Acta botanica brasilica, 24(4), 1034-1045.

Fischer, D., et al.(2003). In vitro cytotoxicity testing of polycations: influence of polymer structure on cell viability and hemolysis. Biomaterials, 24, 1121 1131 .

Ahmed, S. A. et al.(1994). A new rapid and simple non-radioactive assay to monitor and determine the proliferation of lymphocytes: an alternative to [3H]thymidine incorporation assay. Journal of Immunological Methods, 170, 211-224.

Gil, E. S. (2007). Controle físico-químico de qualidade de medicamentos. (2a ed.),

Martins, M. D. (2009). Citotoxicidade in vitro de extratos de arnica brasileira (Solidago microglossa) e arnica paulista (Porophyllum ruderale). ConScientiae Saúde, 8(1),99104.

Marreiro, R. O., et al. (2014). Cytotoxicity evaluation of a mouthwash containing extract of Libidibia ferrea. BRPDIC,3, 34-42.

Vênâncio, G. N., et al. (2020). Cytotoxicity and antimicrobial activity of mouthwash obtained from the extract of Libidibia ferrea Mart. Brazilian Journal of Development. 6(9), 69828-69841.

Brasil. (2004). Ministério da Saúde. Agência Nacional de Vigilância Sanitária (ANVISA) Resolução de Diretoria Colegiada no. 48 de 16 de março de 2004. Aprova o regulamento técnico de medicamentos fitoterápico junto ao Sistema Nacional de Vigilância Sanitária. DOU. Diário Oficial da União, Poder Executivo.

Pereira, C. T., et al. (2020). Análise da citotoxicidade do extrato metanólico de Psidium guineense Swartz em células sanguíneas humanas. Research, Society and Development, $9(6), 5$. 